\title{
Overheating in Scotland: contributing factors in occupied homes.
}

C. Morgan ${ }^{\mathrm{a}, \mathrm{b}}$, J. A. Foster ${ }^{\mathrm{a}}$, A. Poston ${ }^{\mathrm{a}, \mathrm{c}}$ and T. R. Sharpe ${ }^{\mathrm{a}}$

${ }^{a}$ Mackintosh Environmental Architecture Research Unit, Glasgow School of Art, Glasgow, UK; ${ }^{\text {b John }}$ Gilbert Architects, Glasgow, UK; ${ }^{\mathrm{c}}$ School of Engineering and Built Environment, Glasgow Caledonian University, Glasgow, UK.

\section{Abstract}

There is growing awareness of the overheating risks in new-build properties in the UK. However, this tends to be considered a problem principally for the southern regions in the UK, only becoming a serious issue in the North of England in the medium term and in the long term for Scotland. This notion tends to be largely predicated upon climate change predictions, differences in latitude and summer air temperatures. This paper describes the results from Building Performance Evaluation (BPE) studies over a two-year period from 26 occupied new-build homes across Scotland which demonstrated incidences of overheating. Results suggest that low energy buildings are susceptible to overheating despite northerly latitudes, with $54 \%$ of houses studied overheating for more than six months annually, and $27 \%$ of homes overheating for less than $10 \%$ of the year. Evidence indicated that commonly used prediction tools do not appear to adequately anticipate overheating. This paper maps common overheating causes due to design and the role of occupants, identifying the risks due to the regulatory system, prediction and procurement processes, and the design and construction. A common finding was that design and occupancy factors appear to greater impact on overheating more than location and climatic factors.

Keywords: Overheating, Building Evaluation, Design, Occupant behaviour, Low energy buildings, Passive House, Scotland.

\section{Introduction}

In recent years in the UK, responses to climate change by government (Parliament of the United Kingdom [UK], 2008; Scottish Parliament, 2009) and the construction industry (Parliament of the UK, 2006a) have led to improvements in building standards (Her Majesties Government [HMG], 2013; Scottish Government, 2015) and zero carbon reduction targets (Parliament of the UK, 2006b, p. 168). This has resulted in a 
transformation of UK housing and manufacture, leading to improved insulation levels, airtightness, performance and technologies (National House Building Council [NHBC], 2015). However, these changes have not always been accompanied by industry-wide capacity, understanding or skills, nor by occupant understanding of some of the new strategies and technologies (NHBC, 2015).

Davies \& Oreszczyn (2012) raised concerns about the unintended consequences of rapid change in the construction industry, which include summer overheating. A growing body of research in recent years has led to the identification of a number of variances between design intentions and as built performance in new building types which need to be addressed (Zero Carbon Hub [ZCH], 2014; NHBC, 2012; ZCH, 2015a). These variations tend to be known collectively as constituting a 'Performance Gap’ between intended or predicted, and real or monitored outcomes (ZCH, 2014). Building Performance Evaluation (BPE) is used to identify the performance gap of buildings, and the impact of this may have on energy consumption and occupants (Stevenson \& Leaman, 2010).

\section{Overheating Concern}

Within the context of dwellings in the UK, one acknowledged issue is that of overheating (NHBC, 2012; ZCH, 2015a). However, this has mostly been identified as a problem in the South of the UK with overheating occurring in the North and in Scotland by the middle of the century due to an increase in external temperature due to climate change (Department for Communities and Local Government [DCLG], 2012, p. 35). Dynamic simulation of future climates in different building types by Peacock, Jenkins and Kane (2010) suggested that overheating in Edinburgh is a low risk particularly in buildings with thermal mass. These studies typically base their conclusions on the results of virtual modelling taking into account known patterns of summer temperatures, 
linked to latitude and future climate change predictions. Beizaee, Lomas and Firth (2013) studied overheating risk in English homes during summer, they found that the least warm homes were in the North East, North West and Yorkshire. However, they recommended for more research to be undertaken as to what temperatures are acceptable in English regions. Despite this, there is growing practice based evidence of overheating in Scotland and comparable northern latitude countries. McLeod, Hopfe, and Kwan (2013) suggest that Passive House and other super-insulated dwellings are already at risk of overheating in the UK, Ireland and Northern Europe. Morgan, Foster, Sharpe, and Poston (2015) suggest that there is increasing evidence of overheating already occurring in Scotland.

There is growing evidence of overheating in low energy and Passive House properties in other northern latitude countries. Larsen and Jensen (2011) monitored 10 Passive House dwellings in Skibet, Denmark (latitude is $55.7^{\circ} \mathrm{N}$, Glasgow's latitude is $55.9^{\circ} \mathrm{N}$ ) for three years, commencing October 2008; all homes were found to have severely overheated during the 2009 and 2010 summers. Their overheating assessment used the Danish Standards Authority "Ventilation for building - Design criteria for the indoor environment” with the acceptable Category B temperature range of $23-26^{\circ} \mathrm{C}$ selected for assessment. Analysis of one home indicated that during July and August the Category B temperature was exceeded 40\% and 60\% of the time during 2009 and 2010 respectively; this level of overheating was not predicted by the Passive House Planning Package (PHPP) model which uses a temperature of $25^{\circ} \mathrm{C}$ as its overheating threshold. A study by Ruud and Lundin (2004) in Lindas, Sweden (latitude of $57.2^{\circ} \mathrm{N}$, Inverness' latitude is $57.5^{\circ} \mathrm{N}$ ) found mean temperatures across 20 terraced apartments of $25.2^{\circ} \mathrm{C}$, however temperatures were variable and some exceeded $30^{\circ} \mathrm{C}$. 
Further north in Estonia ( average latitude $59^{\circ} \mathrm{N}$, around the same as the Scottish Orkney Islands), Maivel, Kurnitski \& Kalamees (2014) note that while overheating has not been considered an issue in Nordic countries, new buildings are changing and they compare increased levels of overheating in newer apartments compared to older ones. The Estonian regulations have a criterion for overheating, based on excess degree hours over $27^{\circ} \mathrm{C}$. This was exceeded $13.7 \%$ of the time in new apartments that were monitored.

Given that overheating is occurring in well insulated buildings in northern latidudes now and not under future climate scenarios, it follows that the causes of this needs further study, not only because it might represent additional energy consumption, but also due to the known risk that overheating represents to the comfort and health of occupants, , especially to the more vulnerable sections of society (Office of the Deputy Prime Minister [ODPM], 2006; Kovats \& Hajat, 2008; NHBC, 2012).

\section{Overheating Definition \& Calculation}

The assessment of overheating can be in relation to thermal comfort, health or productivity. As a result various evidence-based overheating thresholds are used by different disciplines with incomparable metrics (ZCH, 2015b, p. 2). Peacock et al. (2010) and ZCH (2015a) highlight that there is currently no precise definition of overheating of dwellings in the UK. A limitation of fixed temperature thresholds is that they do not take variation of occupancy comfort levels in relation to other factors and external temperatures into consideration (ZCH, 2015a). Use of adaptive comfort models such as CIBSE TM52 are limited as they are currently based on non-domestic evidence and testing is required as to the appropriateness for night-time comfort in bedrooms (ZCH, 2015a). A survey of housing providers by ZCH (2015, p. 36) found that fixed thermal comfort definitions for overheating assessment were derived variously from the 
Standard Assessment Procedure (SAP) Appendix P, CIBSE Guide A (2006) and Passive House Institute design criteria.

SAP is the UK Government's adopted means of assessing and comparing environmental and energy performance of dwellings and is primarily used as a threshold within the building regulations in each of the four constituent countries of the UK to assess compliance with the energy efficiency requirements of that country. Although it is primarily used as a compliance tool and contains a number of default assumptions, the data derived from these assessments is often used to underpin national policy initiatives (ZCH, 2015c). Appendix P of SAP provides an overheating check which uses predicted design and performance data to calculate the predicted average internal temperature for June, July and August, with overheating risk defined as slight between $20.5-22^{\circ} \mathrm{C}$, medium between $22-23.5^{\circ} \mathrm{C}$ and high when greater than $23.5^{\circ} \mathrm{C}(\mathrm{ZCH}$, 2015a; ZCH, 2015c).

As with SAP, the PHPP overheating calculation method is also a monthly calculation however PHPP uses a dynamic single zone building model where risk of overheating is based on exceedance of a fixed internal temperature threshold of $25^{\circ} \mathrm{C}$. The difference between the two methods is PHPP's use of a full calendar year and historical weather files for the assessment of solar gains, whereas SAP overheating criteria is based three summer months data, is independent of location and uses floor area assumptions for internal gains (ZCH, 2015c). An internal temperature of $25^{\circ} \mathrm{C}$ is an important health threshold identified in the UK Government Housing Health and Safety Rating System (HHSRS) (ODPM, 2006; ZCH, 2015). This temperature threshold is also used by the Passivhaus Institute in their PHPP software (Certified European Passive House [CEPH], 2014), to indicate risk of overheating during the design phase. For certification of Passive Houses, the PHPP temperature threshold may not exceed $25^{\circ} \mathrm{C}$ 
for more than $10 \%$ of the year. Bearing in mind climate change predictions and the fact that $10 \%$ of a year is a long time for a property to be overheating, good practice within the Passive House community acknowledges that less than 5\% overheating annually is acceptable practice while ideally Architects and designers should aim for $0 \%$ exceedance of the temperature threshold annually (CEPH, 2014 p. 79, BRE 2011).

Due to the health risks associated with temperatures that exceed $25^{\circ} \mathrm{C}$ the Passive House overheating criterion has been selected for use in this study. Temperatures have been noted in this paper without associated reference to relative or absolute humidity measurements. Relative humidity readings were taken as part of the monitoring of all properties but are rarely used in discussion of overheating generally and have not been used in this paper to avoid confusion.

\section{Project information}

The case studies in this paper represent six separate sites across Scotland with a total of 26 occupied homes (see Table 1 and Figure 1) all of these dwellings were participating in the $£ 8 m$ Innovate UK (IUK) funded BPE studies and were located in rural and urban areas. The rural sites are located in Lockerbie, Dunoon and Inverness; the urban sites in Barrhead, Livingston and Glasgow. Of the 26 homes, 20 were provided for affordable rent and six were owner occupied and sold to the occupants under a shared equity scheme. The dwellings were designed and constructed as affordable Passive House dwellings (5no.) and low energy housing (21no.) these were subjects of the Phase 2 of the IUK BPE project that required data collection for a two year period. The objective of the BPE was to compare the designed performance against the actual indoor environmental conditions, energy consumption and fabric performance of new occupied domestic and non-domestic buildings across the UK. The data analysed for this paper represents one full calendar year (2013) to allow comparison across the various sites, as 
the project start and end dates were not synchronised.

Table 1. Basic data for the 26 monitored homes.

\begin{tabular}{|c|c|c|c|c|c|c|c|}
\hline Site & Code & $\begin{array}{l}\text { Home } \\
\text { type }\end{array}$ & Built Form & $\begin{array}{l}\text { Occupants } \\
\text { (A=adult, } \\
\text { C = child) }\end{array}$ & $\begin{array}{l}\text { Floor } \\
\text { Area }\left(\mathrm{m}^{2}\right)\end{array}$ & $\begin{array}{l}\text { No. of } \\
\text { Bedrooms }\end{array}$ & Storeys \\
\hline \multirow[t]{2}{*}{ Lockerbie } & DA1 & House & Semi-detached & $1 \mathrm{~A} 1 \mathrm{C}$ & 87.00 & 2 & 2 \\
\hline & DA2 & House & Semi-detached & $1 \mathrm{~A} 1 \mathrm{C}$ & 87.00 & 2 & 2 \\
\hline \multirow{2}{*}{$\begin{array}{l}\text { Latitude } 55.1 \text {; } \\
\text { Longitude } 3.4\end{array}$} & DB1 & House & Semi-detached & $3 \mathrm{~A}$ & 102.77 & 3 & 2 \\
\hline & DB2 & House & Semi-detached & $2 \mathrm{~A}$ & 102.77 & 3 & 2 \\
\hline \multirow{3}{*}{$\begin{array}{l}\text { Dunoon } \\
\text { Latitude 55.9; } \\
\text { Longitude 4.9 }\end{array}$} & TB1 & House & Semi-detached & $1 \mathrm{~A} 1 \mathrm{C}$ & 104.00 & 2 & 2 \\
\hline & TA1 & House & Semi-detached & $2 \mathrm{~A} 3 \mathrm{C}$ & 120.00 & 3 & 2 \\
\hline & TA2 & House & Semi-detached & $2 \mathrm{~A} 2 \mathrm{C}$ & 120.00 & 3 & 2 \\
\hline \multirow{6}{*}{$\begin{array}{l}\text { North } \\
\text { Glasgow } \\
\text { Latitude 55.9; } \\
\text { Longitude 4.3 }\end{array}$} & GA1 & Flat & Flat - ground floor & $1 \mathrm{~A}$ & 51.00 & 1 & 1 \\
\hline & GA2 & Flat & Flat - mid floor & $1 \mathrm{~A}$ & 51.00 & 1 & 1 \\
\hline & GA3 & Flat & Flat - top floor & $1 \mathrm{~A}$ & 53.00 & 1 & 1 \\
\hline & GB1 & Flat & Flat - ground floor & $1 \mathrm{~A}$ & 66.00 & 2 & 1 \\
\hline & GB2 & Flat & Flat - top floor & 2A 1C & 66.00 & 2 & 1 \\
\hline & GB3 & Flat & Flat - ground floor & $2 \mathrm{~A} 1 \mathrm{C}$ & 73.30 & 2 & 1 \\
\hline \multirow{2}{*}{$\begin{array}{l}\text { Livingstone } \\
\text { Latitude 55.9; } \\
\text { Longitude } 3.5\end{array}$} & LA5 & House & Mid-terrace & $3 \mathrm{~A}$ & 104.00 & 3 & 2 \\
\hline & LA6 & House & End-terrace & $3 \mathrm{~A}$ & 104.00 & 3 & 2 \\
\hline \multirow{3}{*}{$\begin{array}{l}\text { Barrhead } \\
\text { Latitude 55.8; } \\
\text { Longitude 4.4 }\end{array}$} & BA1 & House & Mid-terrace & $2 \mathrm{~A}$ & 93.09 & 2 & 2 \\
\hline & BB2 & Flat & Flat - top floor & $2 \mathrm{~A}$ & 75.80 & 2 & 1 \\
\hline & BC1 & House & End-terrace & $2 \mathrm{~A}$ & 75.44 & 2 & 1 \\
\hline \multirow{8}{*}{$\begin{array}{l}\text { Inverness } \\
\text { Latitude 57.4; } \\
\text { Longitude } 4.2\end{array}$} & IA1 & House & End-terrace & $2 \mathrm{~A} 4 \mathrm{C}$ & 110.00 & 3 & 2 \\
\hline & IA2 & House & Mid-terrace & $1 \mathrm{~A} 5 \mathrm{C}$ & 110.00 & 3 & 2 \\
\hline & IB1 & House & Semi-detached & $2 \mathrm{~A} 2 \mathrm{C}$ & 90.00 & 3 & 2 \\
\hline & IB2 & House & Semi-detached & $2 \mathrm{~A} 2 \mathrm{C}$ & 90.00 & 3 & 2 \\
\hline & IC1 & Flat & Flat - ground floor & $1 \mathrm{~A}$ & 63.00 & 1 & 1 \\
\hline & IC2 & Flat & Flat - Top Floor & $2 \mathrm{~A}$ & 63.00 & 1 & 1 \\
\hline & ID1 & Flat & Flat - ground floor & $2 \mathrm{~A}$ & 76.00 & 2 & 1 \\
\hline & ID2 & Flat & Flat - ground floor & $2 \mathrm{~A}$ & 76.00 & 2 & 1 \\
\hline
\end{tabular}

Note: Grey shading denotes Passive Houses 


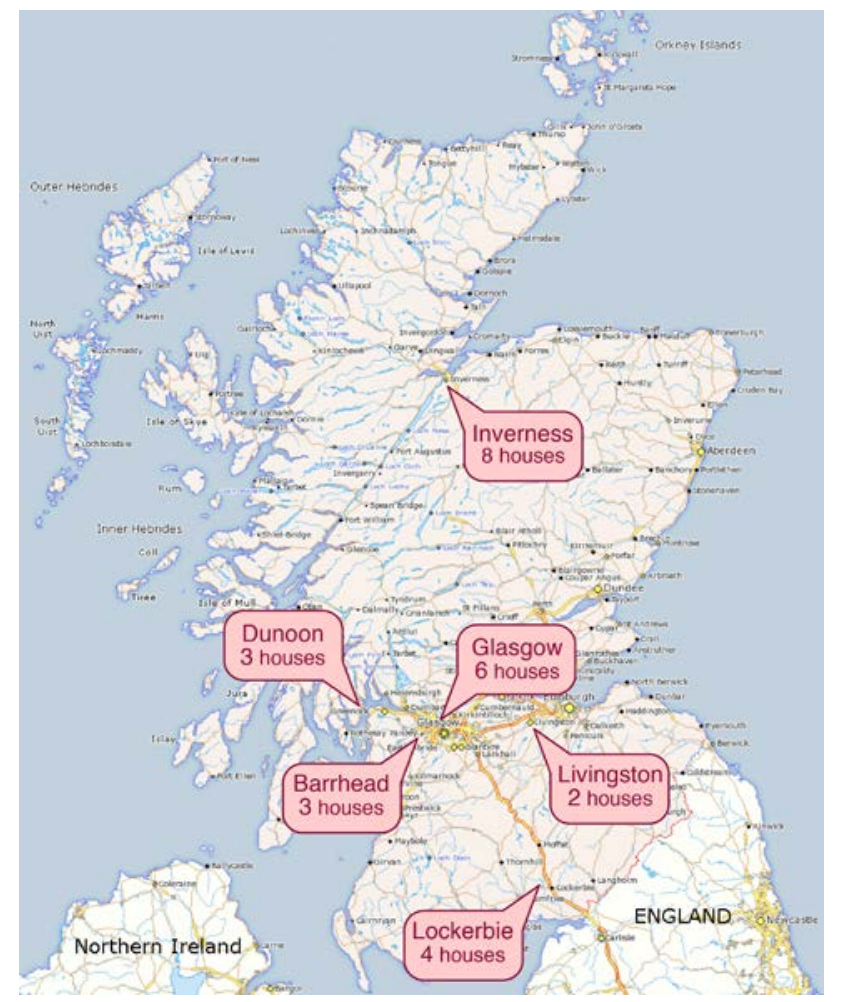

Figure 1. Locations of the 26 monitored homes across Scotland.

\section{Methodology}

The internal temperature in three different rooms were monitored in each home during the calendar year of 2013, this data is represented as a percentage of each month the temperature exceeded the thermal threshold for an overall representation of the whole house for each home. This is represented to allow comparison with the single whole house volume of the Passive House standards. Monitoring of temperatures in the living room and master bedroom was common to all properties and this data provides a comparison of internal temperature for two rooms that form the main focus of this study.

It should be noted that although the UK weather on average in 2013 was average, significant weather events occurred including a late cold spring with unseasonable snowfalls. The summer was sunny and warm with heatwave conditions in July with external temperatures $1.9^{\circ} \mathrm{C}$ above the $1981-2010$ average. October and 
December were stormy with high winds and rainfall (Met-Office, 2016). Whilst 2013 could be seen as slightly anomalous in the context of the preceding and surrounding years, it is nonetheless perhaps more representative of the years to come with more extreme weather events and predicted global surface temperature increases of $0.3^{\circ} \mathrm{C}$ to $0.7^{\circ} \mathrm{C}$ between $2016-2035$ and $1.5^{\circ} \mathrm{C}-2^{\circ} \mathrm{C}$ between $2081-2100$ (IPCC 2014).

Indoor environmental monitoring data was collected via EnOcean Wireless Sensor Technology (WiST) using combined wall-mounted sensors to provide readings representative of the occupied rooms. These were positioned around $1.6 \mathrm{~m}$ from finished floor level in locations away from draughts, heat sources and direct sunlight. The sensors measured internal temperature $\left({ }^{\circ} \mathrm{C}\right)\left(0-51^{\circ} \mathrm{C}\right.$ range, accuracy $\pm 0.5^{\circ} \mathrm{C}$ over full range), Relative Humidity $(\mathrm{RH})(0-100 \%$ range, accuracy $\pm 1.5 \%$ over full range) and Carbon Dioxide $\left(\mathrm{CO}_{2}\right)$ concentration $(0-5000 \mathrm{ppm}$ range, accuracy $\pm 50 \mathrm{ppm}$ over full range with auto-calibration every eight days). Wireless solar powered window contact sensors were used to monitor window opening occurrences in the rooms subjected to environmental monitoring. Data from these apparatus was transmitted via Modbus Receiver Unit every five minutes throughout the monitoring period to a central off-site server, transmitting data over General Packet Radio Service (GPRS) networks.

Mains powered repeater units with internal antenna were positioned centrally in each dwelling to boost signals and improve reliability of data transfer. However, transmission problems were encountered at one of the rural sites due to lack of GPRS network reception. In these dwellings the data transfer was made via an Ethernet connection. A manual data cleansing process was adopted, where missing or corrupt data was amended using averages from readings immediately before and after the interruption. In dwelling DA1, large gaps in the data were detected effecting three months of data, these incomplete months were excluded from analysis. 
Additional studies informing this research were occupant interviews and questionnaires, these consisted of semi-structured interviews delivered by the research team, as well as a detailed understanding of the building fabric, made through a number of non-destructive surveys in adherence to the requirements of the BPE programme.

The data is represented in two ways. The first is through the use of measured, quantitative data representing recorded temperatures from the monitored rooms. Secondly, a matrix of overheating factors was developed, based on a mixed methods approach, mapping a range of potential circumstances, design aspects and known occupancy behaviour factors which could lead to overheating in living rooms and master bedrooms in the 26 dwellings monitored.

The matrix provides an overview of the range and frequency of these factors rather than an accurate assessment of each. In each case, a point is gained where there is an increased likelihood of overheating against a nominal UK average or for example where a measure has, or has not been taken, for example, provision of external shading on a South-facing window. Unlike computer modelling processes, the monitoring process does not allow for disaggregation or individual measurement of each factor. It is recognised that this study comprises a limited sample of dwellings from which to draw definitive conclusions, particularly for Passive House, with a limited geographical spread. The aim of this study is to use the data collected to illustrate the issues in relation to overheating that are arising in new homes in Scotland; and to demonstrate that overheating of dwellings is a current problem in Scotland.

\section{Results}

Table 2 depicts the results of the temperature monitoring at five minute intervals across all dwellings in 2013. The results represent the mean temperature across the whole (monitored) house, indicating the total percentage of time for each month and total year 
that the temperature in the house was over $25^{\circ} \mathrm{C}$. This is in keeping with the Passive House criteria whereby: $0-5 \%$ of time annually over $25^{\circ} \mathrm{C}$ is considered acceptable, anything over $10 \%$ of time annually is considered for the building to have overheated. Total time over $30 \%$ is also depicted in the study to demonstrate the severity of overheating experienced in some homes, this represents the equivalent of overheating continuously for more than three months.

Table 2. Percentage of time the whole (monitored) dwelling is overheating $\left(>25^{\circ} \mathrm{C}\right.$ ) by month.

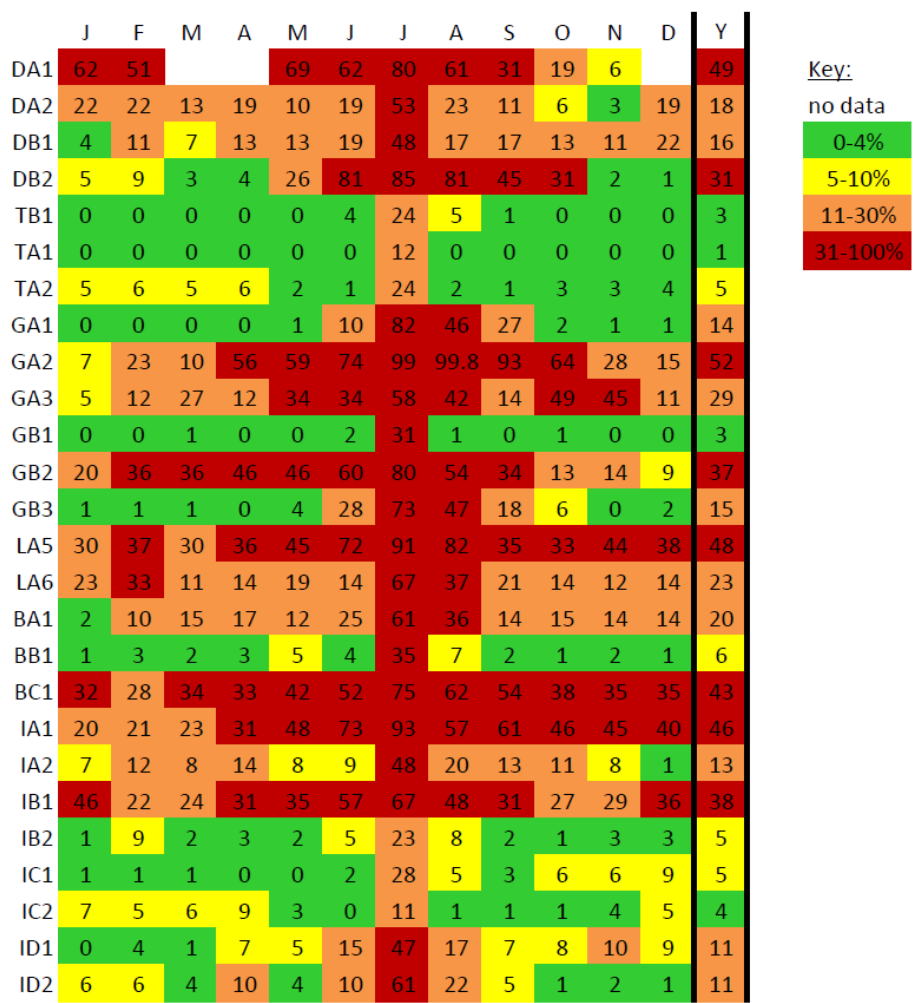

Two findings are evident from this table. The first is the high levels of overheating recorded generally, and the second is that this overheating - in certain properties appears to be spread widely throughout the year. In a domestic context, this calls into question the general assumption that overheating is only a summer issue caused by external temperature.

With each of the five homes demonstrating the highest levels of overheating (DA1, GA2, LA5, BC1 and IA1 - over 40\%) from different regions in Scotland, there is 
no overall trend relating overheating incidence to location, except perhaps in the case of Dunoon, which is discussed below.

Of the five Passive House projects, one registered the second highest levels of overheating (DA1, 49\%), while another registered the second lowest level (TB1, 3\%). All of the Lockerbie projects had levels of overheating above the $10 \%$ threshold acceptable for Passive House compliance in reality, whereas the incidence of overheating predicted in their PHPP calculation was $0.2 \%$. Overall however, it cannot be said that the Passive Houses fare particularly well or badly in comparison to the other homes.

The general rise of overheating in the summer months may be expected but the significant peak of overheating recorded in the month of July is noticeable and in some cases it appears anomalous. Table 3 displays the combined mean internal monthly and annual temperatures of the living rooms and master bedrooms for each dwelling. July exhibits the highest mean temperatures with $60 \%$ of rooms overheating, with mean temperatures as high as $29.5^{\circ} \mathrm{C}$ (GA2 - Bedroom) and $28.3^{\circ} \mathrm{C}$ (GB2 Living Room). Of all of the rooms, $56 \%$ of living rooms and $68 \%$ of bedrooms were revealed to be overheating when compared with Passive House criteria. These temperatures may be a result of the July 2013 heatwave, with an average UK external temperature of $17^{\circ} \mathrm{C}$, $1.9^{\circ} \mathrm{C}$ above the average (Met-Office, 2016), as only $25 \%$ of rooms exhibited overheating out with this period. However, temperature patterns in adjacent months indicate that in the majority of homes, high mean temperatures were still achieved, but the mean was below the $25^{\circ} \mathrm{C}$ threshold. 
Table 3. Combined mean internal monthly and annual temperature $\left({ }^{\circ} \mathrm{C}\right)$ in the living rooms and master bedrooms of all dwellings.

\begin{tabular}{|c|c|c|c|c|c|c|c|c|c|c|c|c|c|c|}
\hline & & J & $F$ & M & A & M & J & J & A & S & 0 & $\mathrm{~N}$ & D & $Y$ \\
\hline DA1 & LR & 22.9 & 21.6 & & & 24.4 & 24.4 & 25.9 & 24.5 & 23.5 & 22.7 & 20.6 & & 23.4 \\
\hline DA1 & Bed1 & 26.9 & 25.7 & & & 26.6 & 26.3 & 27.6 & 25.7 & 24.6 & 23.7 & 22.3 & & 25.5 \\
\hline DA2 & LR & 23.8 & 23.2 & 22.9 & 23.3 & 22.1 & 23.4 & 25.5 & 23.7 & 22.7 & 20.2 & 21.5 & 20.9 & 22.9 \\
\hline DA2 & Bed1 & 24.1 & 24.3 & 23.7 & 23.9 & 23.1 & 24.3 & 26.5 & 24.8 & 23.8 & 21.3 & 22.4 & 21.8 & 23.8 \\
\hline DB1 & LR & 21.6 & 22.9 & 22.4 & 23.1 & 23.0 & 23.4 & 24.4 & 23.9 & 23.7 & 23.7 & 22.7 & 23.3 & 23.3 \\
\hline DB1 & Bed1 & 22.3 & 23.2 & 23.1 & 23.3 & 23.8 & 24.7 & 25.6 & 24.3 & 24.0 & 23.6 & 23.1 & 23.3 & 23.8 \\
\hline DB2 & LR & 22.8 & 23.1 & 22.6 & 22.7 & 24.2 & 25.1 & 26.2 & 25.3 & 24.7 & 24.4 & 22.2 & 22.0 & 24.2 \\
\hline DB2 & Bed1 & 22.4 & 22.7 & 21.9 & 22.3 & 24.0 & 25.8 & 27.0 & 25.6 & 24.8 & 24.2 & 21.5 & 20.7 & 24.2 \\
\hline TB1 & LR & 18.5 & 18.4 & 17.5 & 18.8 & 19.6 & 21.6 & 22.7 & 22.2 & 20.2 & 18.8 & 17.3 & 17.7 & 19.9 \\
\hline TB1 & Bed1 & 19.3 & 19.3 & 18.6 & 19.7 & 20.8 & 22.6 & 24.0 & 23.3 & 21.1 & 19.5 & 17.7 & 18.0 & 20.8 \\
\hline TA1 & LR & 21.9 & 22.0 & 22.5 & 22.5 & 21.7 & 22.4 & 23.5 & 22.4 & 21.9 & 20.6 & 21.8 & 21.8 & 22.0 \\
\hline TA1 & Bed1 & 19.8 & 20.1 & 20.3 & 20.9 & 21.0 & 22.0 & 23.5 & 21.2 & 21.0 & 19.6 & 19.8 & 19.4 & 20.9 \\
\hline TA2 & LR & 23.7 & 23.8 & 23.4 & 23.2 & 22.4 & 21.6 & 22.8 & 22.0 & 21.8 & 22.8 & 23.4 & 23.3 & 22.7 \\
\hline TA2 & Bed1 & 21.5 & 21.4 & 20.6 & 21.4 & 22.0 & 22.1 & 24.2 & 22.5 & 21.6 & 21.6 & 21.5 & 21.4 & 22.0 \\
\hline GA1 & LR & 22.2 & 21.9 & 21.3 & 21.9 & 22.6 & 23.7 & 26.0 & 24.5 & 24.2 & 23.3 & 22.7 & 22.5 & 23.5 \\
\hline GA1 & Bed1 & 22.2 & 22.4 & 21.9 & 22.4 & 23.2 & 24.4 & 26.5 & 25.0 & 24.3 & 23.4 & 22.8 & 22.4 & 23.8 \\
\hline $\mathrm{GA} 2$ & LR & 22.6 & 23.5 & 22.9 & 24.3 & 24.5 & 24.9 & 27.8 & 26.6 & 25.7 & 24.6 & 23.8 & 21.5 & 24.9 \\
\hline GA2 & Bed1 & 23.7 & 24.4 & 23.8 & 25.4 & 25.3 & 26.5 & 29.5 & 28.0 & 26.6 & 25.6 & 24.7 & 22.9 & 26.1 \\
\hline GA3 & LR & 23.3 & 23.1 & 24.1 & 23.4 & 25.4 & 24.5 & 25.9 & 24.8 & 22.9 & 25.3 & 25.0 & 20.8 & 24.5 \\
\hline GA3 & Bed1 & 23.4 & 23.7 & 24.4 & 24.0 & 25.5 & 25.1 & 26.5 & 25.5 & 23.6 & 25.7 & 26.0 & 21.8 & 25.0 \\
\hline GB1 & LR & 17.0 & 17.4 & 17.5 & 18.6 & 20.2 & 21.4 & 23.8 & 22.4 & 20.8 & 20.4 & 18.3 & 19.4 & 20.2 \\
\hline GB1 & Bed1 & 17.4 & 17.1 & 18.0 & 18.4 & 19.2 & 20.9 & 23.2 & 21.4 & 20.0 & 19.5 & 17.6 & 17.5 & 19.6 \\
\hline GB2 & LR & 25.1 & 26.0 & 26.3 & 25.4 & 25.3 & 25.9 & 28.3 & 25.8 & 25.2 & 23.9 & 23.8 & 23.5 & 25.5 \\
\hline GB2 & Bed1 & 22.3 & 23.2 & 23.2 & 23.7 & 23.6 & 24.2 & 26.8 & 24.7 & 23.9 & 22.7 & 23.0 & 22.6 & 23.8 \\
\hline GB3 & LR & 21.6 & 21.6 & 21.9 & 21.6 & 22.6 & 24.3 & 25.4 & 24.9 & 23.8 & 23.2 & 21.8 & 21.9 & 23.2 \\
\hline GB3 & Bed1 & 20.0 & 21.2 & 21.1 & 21.1 & 22.2 & 24.2 & 25.9 & 24.6 & 24.0 & 22.8 & 20.7 & 19.7 & 22.8 \\
\hline LA5 & LR & 24.8 & 25.1 & 24.7 & 24.8 & 25.1 & 25.4 & 27.0 & 25.9 & 24.9 & 25.1 & 25.4 & 25.2 & 25.4 \\
\hline LA5 & Bed1 & 24.0 & 24.2 & 23.9 & 24.4 & 24.6 & 25.9 & 27.3 & 25.6 & 23.7 & 23.2 & 23.8 & 23.2 & 24.7 \\
\hline LA6 & LR & 23.7 & 24.8 & 24.1 & 23.9 & 23.5 & 23.5 & 25.7 & 24.9 & 24.6 & 23.5 & 24.6 & 24.3 & 24.3 \\
\hline LA6 & Bed1 & 22.9 & 24.3 & 23.5 & 23.7 & 24.3 & 24.3 & 26.2 & 24.8 & 23.7 & 22.9 & 23.7 & 24.2 & 24.1 \\
\hline BA1 & LR & 18.9 & 22.4 & 23.1 & 23.5 & 22.7 & 23.2 & 24.6 & 23.9 & 22.1 & 22.7 & 23.3 & 23.3 & 22.6 \\
\hline BA1 & Bed1 & 17.8 & 19.9 & 20.1 & 21.3 & 21.6 & 23.5 & 25.3 & 23.6 & 21.2 & 21.4 & 19.9 & 19.9 & 21.6 \\
\hline BB1 & LR & 21.0 & 21.4 & 21.2 & 21.9 & 22.4 & 22.3 & 24.2 & 22.8 & 21.4 & 21.3 & 21.0 & 20.9 & 22.0 \\
\hline BB1 & Bed1 & 18.2 & 18.4 & 17.4 & 19.5 & 21.0 & 21.8 & 23.8 & 22.3 & 20.4 & 19.9 & 18.5 & 19.0 & 20.5 \\
\hline $\mathrm{BC} 1$ & LR & 23.2 & 23.0 & 23.5 & 23.8 & 24.3 & 25.0 & 25.7 & 25.3 & 25.3 & 24.3 & 23.6 & 23.8 & 24.4 \\
\hline $\mathrm{BC} 1$ & Bed1 & 22.1 & 22.3 & 22.5 & 22.6 & 23.4 & 24.4 & 25.3 & 24.7 & 24.2 & 22.9 & 22.7 & 22.8 & 23.6 \\
\hline IA1 & LR & 23.8 & 24.3 & 24.1 & 24.2 & 25.1 & 27.1 & 27.9 & 25.8 & 26.0 & 26.1 & 24.6 & 24.7 & 25.6 \\
\hline IA1 & Bed1 & 24.8 & 24.7 & 24.7 & 24.7 & 25.0 & 25.1 & 25.6 & 25.0 & 25.1 & 24.9 & 24.9 & 24.8 & 25.0 \\
\hline IA2 & LR & 23.0 & 23.4 & 23.1 & 23.5 & 23.1 & 23.2 & 24.3 & 23.6 & 23.4 & 23.0 & 23.2 & 22.8 & 23.3 \\
\hline IA2 & Bed1 & 22.9 & 23.7 & 22.4 & 23.5 & 22.8 & 23.8 & 25.3 & 24.2 & 23.6 & 23.8 & 22.9 & 21.3 & 23.7 \\
\hline IB1 & LR & 23.1 & 22.3 & 22.2 & 22.4 & 22.4 & 23.7 & 24.4 & 23.5 & 22.7 & 22.7 & 22.4 & 22.6 & 23.0 \\
\hline IB1 & Bed1 & 24.9 & 24.4 & 24.6 & 23.8 & 23.9 & 25.1 & 25.5 & 24.3 & 23.4 & 23.5 & 23.5 & 23.6 & 24.3 \\
\hline IB2 & LR & 20.8 & 21.7 & 21.1 & 21.7 & 21.7 & 22.0 & 22.9 & 22.4 & 22.0 & 21.8 & 21.7 & 21.5 & 21.9 \\
\hline IB2 & Bed1 & 21.7 & 22.8 & 22.1 & 22.4 & 22.4 & 22.8 & 23.9 & 22.7 & 22.7 & 22.3 & 22.5 & 22.5 & 22.6 \\
\hline IC1 & LR & 20.5 & 21.3 & 18.6 & 20.9 & 18.5 & 22.6 & 24.3 & 22.9 & 21.3 & 21.2 & 19.7 & 19.4 & 21.4 \\
\hline IC1 & Bed1 & 20.2 & 20.8 & 18.1 & 20.1 & 17.4 & 22.2 & 23.7 & 22.5 & 20.8 & 20.2 & 17.4 & 17.3 & 20.6 \\
\hline IC2 & LR & 21.8 & 19.2 & 21.5 & 22.6 & 20.8 & 21.0 & 22.6 & 21.4 & 20.8 & 20.5 & 20.7 & 19.8 & 21.0 \\
\hline IC2 & Bed1 & 19.2 & 17.4 & 19.1 & 20.6 & 19.6 & 20.8 & 22.8 & 21.3 & 20.0 & 19.3 & 18.7 & 19.2 & 19.9 \\
\hline ID1 & LR & 22.6 & 22.8 & 21.9 & 23.3 & 22.8 & 23.8 & 25.7 & 24.1 & 22.7 & 23.9 & 24.1 & 23.8 & 23.6 \\
\hline ID1 & Bed1 & 20.8 & 21.2 & 19.7 & 21.9 & 22.3 & 22.3 & 23.5 & 22.5 & 21.5 & 22.7 & 22.8 & 21.8 & 22.2 \\
\hline ID2 & LR & 22.5 & 22.1 & 21.5 & 22.9 & 22.0 & 22.8 & 25.0 & 23.4 & 22.1 & 20.9 & 20.8 & 21.1 & 22.4 \\
\hline ID2 & Bed1 & 21.9 & 21.9 & 21.6 & 22.6 & 22.6 & 23.3 & 25.7 & 24.5 & 22.9 & 22.0 & 21.1 & 21.2 & 22.9 \\
\hline
\end{tabular}

Key:

No data

Mean temperature $>20<25^{\circ} \mathrm{C}$

Mean temperature $>25^{\circ} \mathrm{C}$

Throughout the whole year, by monthly mean temperature, $25 \%$ of rooms were found to

be overheating for between three and nine months. The total annual data indicated that 
seven rooms were found to have mean annual temperatures which exceeded $25^{\circ} \mathrm{C}$. In both monthly and annual mean data, bedrooms represented $50 \%$ of the overheating. IA1 was the only house which was overheating in both living room and bedroom. These findings are of particular concern as high temperatures in bedrooms do not allow the body to recover from daytime thermal stress (Kovats \& Hajat, 2008). Many of the occupants stated that they opened windows in bedrooms overnight when it was hot, but some, particularly in ground floor flats did not do so due to issues with noise and security.

Table 4 is the matrix, which maps a number of relevant factors relating to overheating in living rooms and bedrooms in all 26 homes while Table 5 describes each factor in more detail. The first three columns in Table 4 indicate basic incidence of overheating with black diamonds as shown more graphically in the preceding tables to allow comparison with the factors shown by red dots. Overheating was predicted in only two of the 26 properties, using the requisite SAP calculation and PHPP assessment for the Passive Houses. The SAP overheating prediction for dwellings ID1 and ID2, indicated a household incidence of $11 \%$ per annum. $64 \%$ of the homes monitored experienced a greater percentage of overheating than those where it had been predicted by SAP. 
Table 4. Overheating Matrix by room.

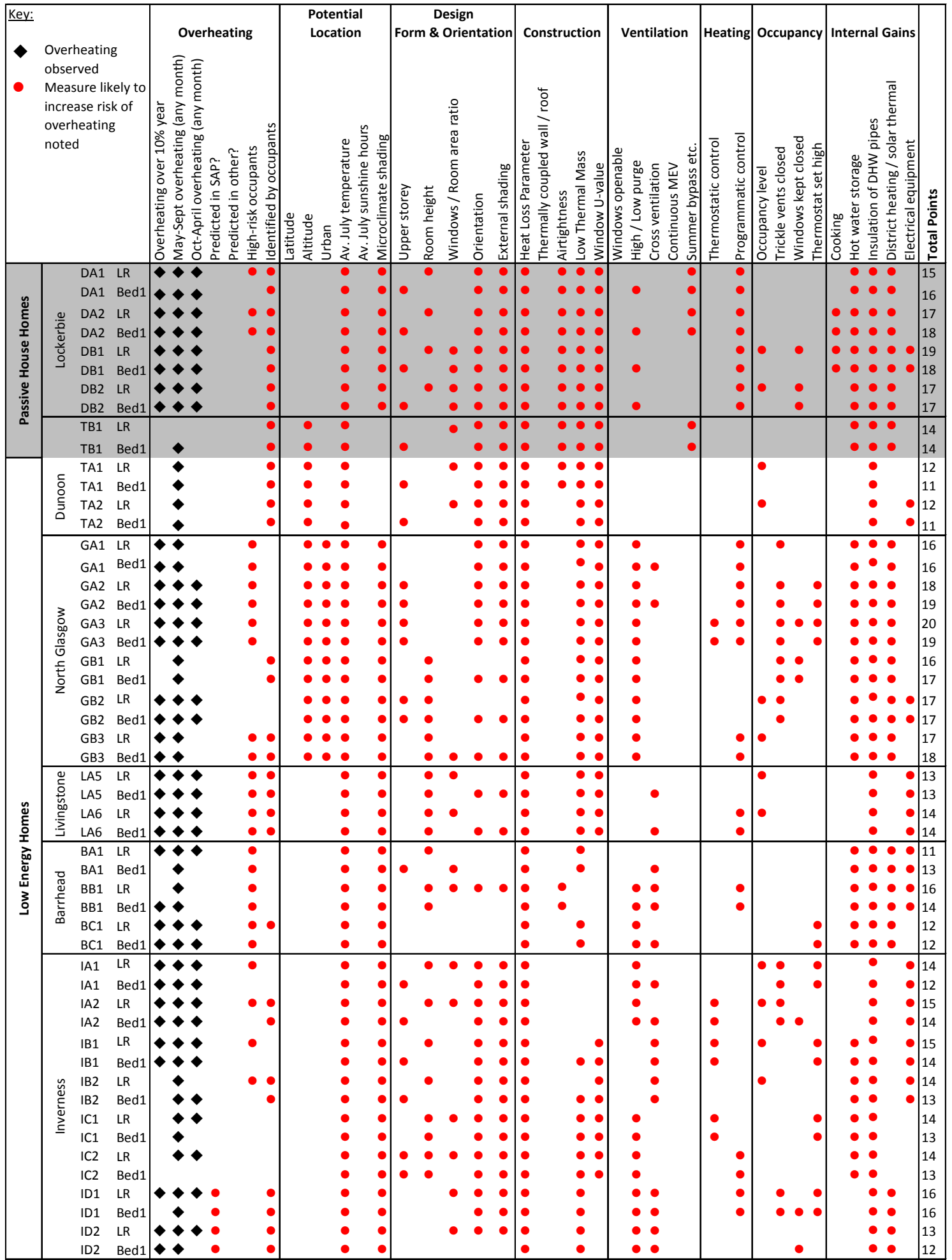


Table 5. Matrix factors and parameters.

\begin{tabular}{|c|c|}
\hline Factor & Parameter \\
\hline \multicolumn{2}{|l|}{ Overheating } \\
\hline Overheating over $10 \%$ year & Point if over $10 \%$ of whole year overheating \\
\hline May-Sept overheating & Point if overheating took place for any month in this period \\
\hline Oct-April overheating & Point if overheating took place for any month in this period \\
\hline Predicted in SAP? & Point if overheating predicted in SAP design calculations? \\
\hline Predicted in Other? & Point if predicted in another tool, e.g. PHPP, dynamic modelling etc. \\
\hline High-risk occupants & $\begin{array}{l}\text { Point if occupants include children, elderly, infirm, other vulnerable. This does not change overheating, but alters the } \\
\text { severity of risk }\end{array}$ \\
\hline Identified by occupants & $\begin{array}{l}\text { Point where occupants themselves have identified overheating as an issue in the room studied or house as a whole. Does } \\
\text { not alter overheating but indicates awareness / concern. }\end{array}$ \\
\hline \multicolumn{2}{|r|}{ ( } \\
\hline Latitude & Point if property is in southern half of UK (none) \\
\hline Altitude & Point if property is below $50 \mathrm{~m}$ altitude \\
\hline Urban & Point if urban location. References potential effect of Urban Heat Island \\
\hline Av. July temperature & Point if greater than UK 2013 average of $17^{\circ} \mathrm{C}$ for July \\
\hline Av. July sunshine hours & Point if greater than UK 2013 average of 249 hours for July \\
\hline Microclimate shading & $\begin{array}{l}\text { Point if no effective microclimate shading. For example: by trees or nearby buildings / high ground which would reduce } \\
\text { direct solar gain }\end{array}$ \\
\hline \multicolumn{2}{|l|}{ Form and Orientation } \\
\hline Upper storey & Point if room is on an upper floor. References potential for stack effect heat gain \\
\hline Room height & Point if ceiling heights are no more than $2.4 \mathrm{~m}$ \\
\hline Windows / Room area ratio & Point if window area / room area ratio is greater than $0.3(30 \%)$ \\
\hline Orientation & Point if windows face East, South or West \\
\hline External shading & Point if no fixed / adjustable shading and facing, East, South or West \\
\hline \multicolumn{2}{|l|}{ Construction } \\
\hline $\begin{array}{l}\text { Heat Loss Parameter (HLP) } \\
\left(\mathrm{W} / \mathrm{m}^{2} \mathrm{~K}\right)\end{array}$ & $\begin{array}{l}\text { Point if HLP less than } 2.1 \mathrm{~W} / \mathrm{m}^{2} \mathrm{~K} \text {. (UK new build average) Heat Loss Parameter = Overall heat loss (fabric + vent) } / \text { total } \\
\text { floor area. Refers to house overall. }\end{array}$ \\
\hline Thermally coupled wall/roof & $\begin{array}{l}\text { Point if thermally coupled fabric (eg solid stone wall). Vented cavity or insulation ‘de-coupling' reduces risk of } \\
\text { overheating via fabric conduction. }\end{array}$ \\
\hline Airtightness & Overall house value, point if tested to below 3.0 m³/h/m²@50Pa \\
\hline Low Thermal Mass & $\begin{array}{l}\text { Point where useful thermal mass exposed internally deemed to be 'low' under SAP assessment. (potential high / medium / } \\
\text { low) }\end{array}$ \\
\hline Window U-value & $\begin{array}{l}\text { Point if windows av. U-value below } 1.4 \mathrm{~W} / \mathrm{m}^{2} \mathrm{~K} \text { (UK Building Standards Minimum standard) relates to potential for } \\
\text { increased heat retention }\end{array}$ \\
\hline \multicolumn{2}{|r|}{ ( } \\
\hline Windows openable & Point if windows cannot be accessed / opened (unusual in domestic, more common in non-domestic) \\
\hline High/Low purge & Point if no designed high / low openings, including accessible rooflights to allow natural purge ventilation \\
\hline Cross ventilation & Point where no capacity for cross ventilation possible \\
\hline Continuous MEV & Point if no continuous extract, ie intermittent only with trickle vents \\
\hline Summer bypass etc. & Point if MVHR is fitted without summer bypass. \\
\hline \multicolumn{2}{|l|}{ Heating } \\
\hline Thermostatic control & Point if no thermostatic control installed or demonstrably not understood by occupants? \\
\hline Programmatic control & Point if no programmatic control installed or demonstrably not understood by occupants? \\
\hline \multicolumn{2}{|l|}{ Occupancy } \\
\hline Occupancy level & Point if occupancy level is above UK average of 2.3, used for living rooms only \\
\hline Trickle vents closed & Point if installed trickle vents inoperative or unused / left closed. \\
\hline Windows kept closed & Point where windows habitually kept closed. May be closed in practice due to security, noise or pollution. \\
\hline Thermostat set high & Point where thermostats knowingly set high ( more than $25^{\circ} \mathrm{C}$ or Thermostatic Radiator Valves (TRVs) on 4 or 5) \\
\hline \multicolumn{2}{|l|}{ Internal Gains } \\
\hline Cooking & $\begin{array}{l}\text { Point if high level of cooking and associated heat gains. Derived from sub-metering of cooker circuit recording more than } \\
30 \mathrm{kWh} / \mathrm{month}\end{array}$ \\
\hline Hot water storage & Point if hot water storage vessel (if present) poorly or not insulated \\
\hline Insulation of DHW pipes & Point if hot water pipework (DHW) generally uninsulated \\
\hline District heating / solar thermal & Point if district heating or solar thermal pipework present and uninsulated \\
\hline Electrical equipment & $\begin{array}{l}\text { Point if medium or high level of incidental gains from electrical equipment, derived from sub-metering of circuits } \\
\text { recording more than } 250 \mathrm{kWh} / \text { month. }\end{array}$ \\
\hline
\end{tabular}

Note: $\mathrm{SAP}=$ Standard Assessment Procedure; MEV=mechanical extract ventilation; $\mathrm{DHW}=$ domestic hot water.

Of the eight properties with more than 30\% overheating, half of the occupants concerned did not consider their home to have overheated, or at least did not consider it a problem. However, most of these occupants had moved from old draughty properties that were typically difficult to heat. Conversely, in the three homes registering the 
lowest percentages of overheating (TA1 - 1\%, TB1 - 3\% and GB1 - 3\%) overheating was identified as an issue in the occupant feedback. TB1 in Dunoon had one of the lowest frequencies of overheating, but the occupant considered her house to have overheated at temperatures of over $22^{\circ} \mathrm{C}$ and took measures to mitigate against this.

Occupants vary considerably in their attitude to overheating. In IA1, the house is recorded as overheating for a total of $46 \%$ of the year, but the occupants did not mention overheating in their feedback. Next door, in identical dwelling IA2, the occupants registered concern about overheating while their home overheated for a comparatively small 13\% of the year. Similarly, IB1 in Inverness overheated for 38\% of the year with no mention of overheating, while identical and adjacent IB2 overheated for only $5 \%$ of the time but the occupants noted overheating in their feedback.

All monitored homes are north of the nominal mid-point of the UK suggesting a lower risk of overheating relative to the UK overall. Those located in Dunoon and North Glasgow were below 50m altitude, the Glasgow homes additionally being within an urban area, both factors which could increase risk of overheating. Only the homes in Dunoon were judged to have microclimate shading, due to high land mass to their immediate West. The three Dunoon homes also have no South facing windows as they form an East-West facing terrace of dwellings, it is worth noting that these homes consistently evidenced lower internal temperatures.

A number of commonly considered factors are indicated in Table 4 within the 'Design Form and Orientation' grouping but no clear trends emerge from this data relating to room size, ceiling height and relationships with window size. Perhaps surprisingly given the significance of solar gain on internal temperature, only 18 of the 52 rooms monitored have a greater than $30 \%$ ratio of window to room size, and the incidence of these does not tally well with the overall incidence of overheating. 
However, of the houses monitored only one (BA1) at Barrhead had any form of external shading, a technique known to deal effectively with solar gain and reduce overheating 'at source'. At this dwelling there is an installed framework onto which a deciduous climbing plant is trained but the climber is not yet well established so its effects are yet to be felt and currently no benefit can be seen. The BPE process highlighted that a number of these dwellings had fixed solar shading initially proposed but was subsequently removed due to value engineering.

The Heat Loss Parameter (HLP) available from all SAP calculations was used as a representative single figure for the overall level of heat loss from each dwelling. HLP is defined as the specific heat loss (W/K) (including both fabric and ventilation losses) divided by the building's internal floor area $\left(\mathrm{m}^{2}\right)$ giving a resultant figure in $\mathrm{W} / \mathrm{m}^{2} \mathrm{~K}$. The UK average for new build is $2.1 \mathrm{~W} / \mathrm{m}^{2} \mathrm{~K}$ (Cooper \& Palmer, 2011) so all of the projects as relatively low energy new builds were some way below this threshold. It is noteworthy that the two highest HLPs ('worst insulated') belong to BC1 and IA1 which also exhibit some of the highest levels of overheating.

Thermal mass is often discussed in relation to reducing overheating so it is worth noting that almost all but three of the properties were built with little thermal mass exposed to the internal spaces. The generally high levels of overheating could support the argument that thermal mass is valuable in reducing overheating if purged correctly, but it should be noted that one of the properties, IA1 in Inverness, deemed to have higher levels of available thermal mass also exhibited one of the highest levels (46\%) of overheating over the year.

Cross ventilation was possible in $65 \%$ of the homes, although a similar majority do not allow for effective stack ventilation, for example a rooflight and ground floor window that can be left open to cool the house overnight. In still and warm weather this 
ventilation method can be more effective than cross ventilation, but in both cases successful ventilation of warm air can be compromised if internal doors are kept closed and do not have sufficient undercuts.

Although the majority of the homes have some form of thermostatic control, about half have no form of programmatic control. In addition, a common finding as part of the occupancy feedback during the research was that occupants did not fully understand their heating and ventilation controls. In some cases, this lack of understanding was exacerbated by the complexity of the systems, the use of unfamiliar renewable technologies and controls, and a number of mistakes made in the installations themselves.

In $42 \%$ of the properties, either trickle vents, or windows, or both, were kept closed at all times, thereby preventing the possibility of effective ventilation. In most cases, this behaviour was associated with those who did not mention overheating in their feedback but that is not the case in six properties (DB1, DB2, GB1, IA2, ID1 and ID2) which raises questions about the level of occupants' understanding of the control mechanisms available to them. A clear correlation can be seen between four households (GA3, IA2, IB1 and IC1) where the thermostatic control was set to a consistently high level, and who did not mention overheating in their feedback. This suggests that in certain households, what is being defined in this paper as overheating could simply be the desired comfort range of some occupants.

Table 4 indicates a high incidence of hot water storage and uninsulated hot water pipework, including 'additional' pipework associated with district heating or a solar thermal system that increase the internal temperature.

Figure 2 maps the incidence of overheating in the properties, against the sum of all overheating factors noted in Table 4. As can be seen clearly, there is no discernible 
correlation between the incidence of potential factors causing overheating, and the monitored levels of overheating which suggests that there is no obvious priorities or evident first lines of enquiry.

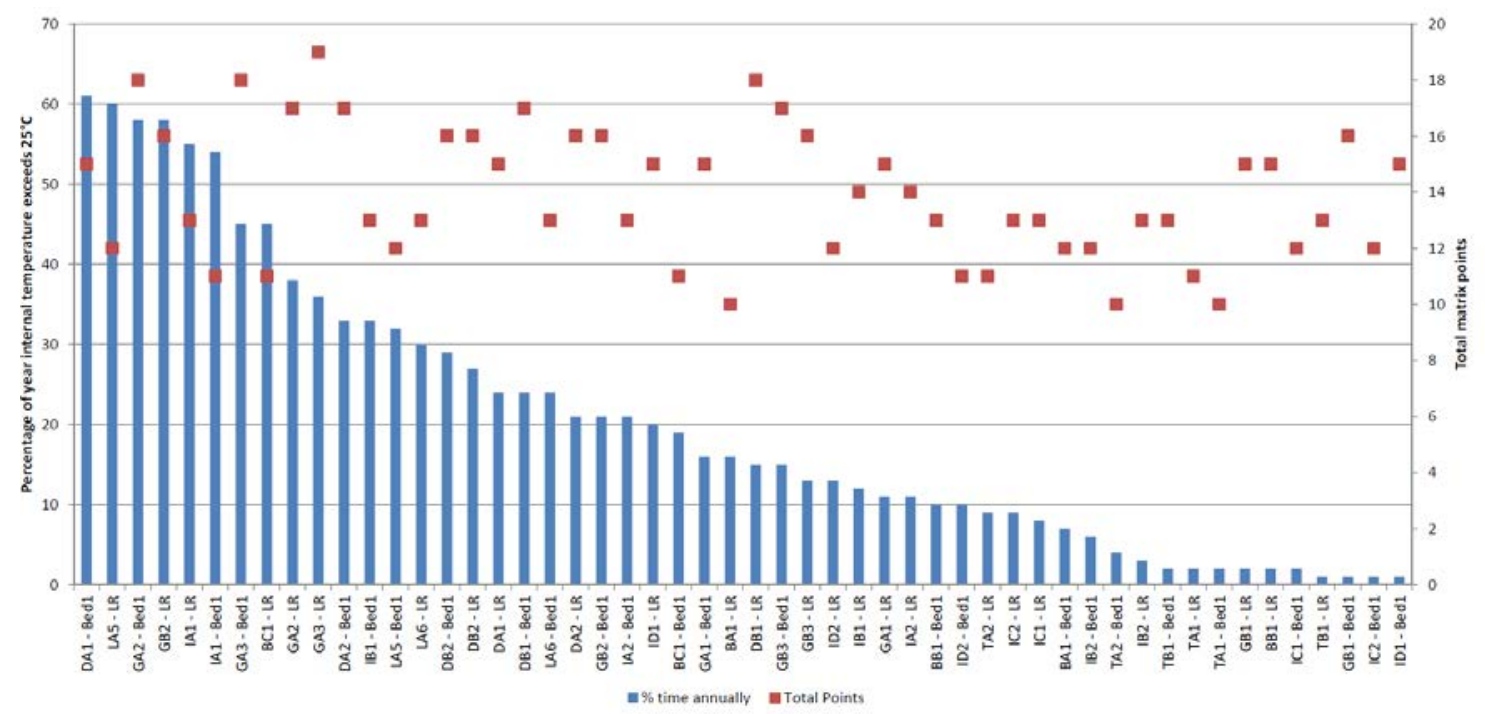

Figure 2. Percentage Overheating versus Matrix total points: by room.

\section{Discussion}

This study analysed temperature data from a sample of 26 new homes built to comply with 2007 and 2010 building (Scotland) regulations, the results indicate that overheating is currently occurring in Scotland. There is no denying that overheating is likely to be a greater problem in the South of the UK both now and in the future, but the evidence presented in this paper counters the notion that overheating is a medium- or long-term problem for the northern parts of the UK and Scotland in particular. The likely consequences of this are that policy makers, clients and those involved in the construction industry in Scotland may put off making the changes to dwelling design that increasing evidence suggests is needed now.

Assuming that all new buildings will be built to similar or improved thermal standards, it is reasonable to suggest that a significant proportion of new properties constructed in the near future without 'future-proofing' against overheating could be 
similarly affected. These buildings will still be occupied in the 2050s and 2080s when climate change modelling suggests that overheating will be as serious in the North of the UK as it is currently becoming in the South of the UK (Peacock et al., 2010). However, to state this with certainty requires a wider study of house types, construction, occupant types, behaviour and geographical location within Scotland, similar to the English study by Beizaee et al. (2013).

The extent of overheating and high mean internal temperatures, represented in Tables 2 and 3 respectively, provides evidence that within the 26 occupied homes, overheating presents a significant issue affecting all of the homes for at least one month per annum, with $54 \%$ of the houses being affected for more than six months and into the heating season. This runs counter to conventional wisdom in which overheating is associated with (external) summer temperatures, increasing with climate change. Over one year only $15 \%$ of houses managed to attain 'acceptable' conditions for less than $4 \%$ of the year and $27 \%$ of houses were found to be below the annual $10 \%$ Passive House overheating threshold, which itself represents the equivalent of more than one continuous month. It should be remembered that the results in Table 2 are averaged over the whole year and include an additional one or two rooms worth of data. In addition, there is no data correlating overheating with occupied hours, nonetheless, these figures give cause for concern.

Comparing properties situated in the same locations and identical in form and construction, it would seem that occupant behaviour appears to be the biggest variable in determining likelihood of overheating. This can be seen when comparing identical or very similar house pairs such as DA1 and DA2, IA1 and IA2 and IB1 and IB2. However, the occupant profiles in two sets of the dwelling pairs (DA1 and DA2 and IB1 and IB2) are marginally different, thus requiring further investigation. 
Another observation of interest is that a number of occupants surveyed do not perceive the measured temperatures to be 'overheating' as such, but desirable conditions of comfort. Thus while a number of properties exhibited significant periods in which temperatures exceeded $25^{\circ} \mathrm{C}$, overheating was not mentioned in occupant feedback. This may be due in part to the occupants having inhabited draughty inefficient homes previously. Conversely, a number of occupants of other households were concerned about overheating, whereas their homes exhibited far lower temperatures in general. Thus occupant perception of overheating, as well as resultant behaviour can be seen as a major factor.

Table 4 takes a broad overview of the factors pertaining to overheating in the 26 properties monitored. Few clear trends can be established but from the perspective of design, the following are of note: none of the properties have any form of effective external shading; only 19\% have any thermal mass exposed to the internal spaces; and $38 \%$ of rooms have potential for stack ventilation. In addition, it appears that hot water pipework is not being effectively insulated and many occupants do not clearly understand heating controls i.e. of those studied, $46 \%$ did not understand or use programmatic control and 15\% did not understand or adjust thermostatic controls.

Focused studies, particularly those based on modelling are valuable in that they enable the community of interest to understand the relative contribution of different factors within a controlled set of variables. previous studies have concentrated on locational and future climate change scenarios (Beizaee et al., 2013; Peacock et al., 2010; Taylor et al., 2014), others have looked at constructional options and thermal mass (Adekunle \& Nikolopoulou , 2016) while others have examined occupant control aspects in detail (Nicol \& Humphreys, 2002). Whilst research based on monitoring of occupied homes may not allow us to identify the relative contribution of each factor, it 
has demonstrated that much design prediction modelling fails to take account of the myriad of design factors and in particular variations in occupant behaviour. By mapping potential causes, both the range and complexity of possible causes can be identified.

The risks of overheating extend not just to those associated with thermal comfort and health of building occupants, but to the risks of increased electricity consumption from an uptake in air conditioning use (Peacock et al., 2010) to provide comfort cooling. Such an uptake would have a detrimental effect on the UK's attempts to reduce carbon emissions and put greater strain on the National Grid.

Architects and designers can do little about the wider developments of climate change, nor can they change the geography of their projects, but they can affect most of the other factors which tend to increase overheating risk, including the options for occupants. It should also be ensured that these measures are delivered in finished buildings. With an aim to provide buildings which are designed and built to inherently protect against overheating and provide opportunities for occupants to manage residual overheating risk is not difficult, nor costly to do, but requires an awareness of the risks from all of those involved in the built environment.

\section{Conclusions}

This paper intended to address overheating in energy efficient housing in Scotland using data collected through BPE studies and a matrix to identify design and occupant factors. Internal air temperature data collected over a one year period demonstrated that overheating, as defined by the Passive House standard, is occurring to concerning levels in dwellings in Scotland; in some cases this is not limited to the summer months. The matrix developed demonstrates that although there were no clear correlations for overheating there are a number of significant contributing factors in both the design and occupancy that requires to be considered for future developments. In short, design and 
occupancy factors appear to override geography and climate change.

The fact that overheating appears not to be entirely a function of external temperature suggests that other factors are contributing to this phenomenon. Further research needs to be undertaken to demonstrate the interrelationship between contributing factors and overheating risk, which can be used to inform change in policy and construction practices. However, beyond both location and design factors, it appears that the individual behaviour of occupants, derived from varying individual perceptions of what constitutes comfortable conditions, can radically alter the performance of buildings in respect of overheating. Thus identical buildings were seen to perform very differently with different occupant patterns and behaviour. Further BPE research into overheating is required and needs to consider specific granular user data, including: use and understanding of systems and controls, window opening, internal door opening, trickle vent use, occupancy patterns and occupant perceptions.

Awareness by policy makers and the regulatory system, supported by more accurate prediction tools, could create the context within which Architects and designers could easily adjust common strategies, details and specifications with the importance of these communicated to builders and occupants. Crucially, occupants would be able to take simple measures to maintain comfortable conditions and mitigate the effects of climate change for as long as possible.

\section{Acknowledgments}

The authors thank Dr Filbert Musau and Donald Shearer for contributing to the design and installation of two of the projects monitored. They also recognize the valuable contribution made by housing associations and individual households in making this research possible. 


\section{Funding}

This research was funded by the Innovate UK Building Performance Evaluation Programme.

\section{References}

Adekunle, T. O., \& Nikolopoulou, M. (2016). Thermal comfort, summertime temperatures and overheating in prefabricated timber housing. Building and Environment, 103, 21-35. http://doi.org/10.1016/j.buildenv.2016.04.001

Beizaee, A., Lomas, K. J., \& Firth, S. K. (2013). National survey of summertime temperatures and overheating risk in English homes. Building and Environment, 65, 1-17. http://doi.org/10.1016/j.buildenv.2013.03.011

Building Research Establishment [BRE] (2011) Passivhaus Primer: Designer's Guide: A guide for the design team and local authorities. Retrieved from: http://www.passivhaus.org.uk/filelibrary/Primers/KN4430_Passivhaus_D esigners_Guide_WEB.pdf

Certified European Passive House - Developing Group [CEPH]. (2014) Certified European Passive House Designer Course. Volume A: The Passive House Standard. University of Strathclyde.

Cooper, I., \& Palmer, J. (2011). Great Britain’s housing energy fact file, 1-118.

Retrieved from:

https://www.gov.uk/government/uploads/system/uploads/attachment_data/file/4 8195/3224-great-britains-housing-energy-fact-file-2011.pdf

M. Davies and T. Oreszczyn, “The unintended consequences of decarbonising the built environment: A UK case study,” Energy Build., vol. 46, pp. 80-85, 2012.

Department for Communities and Local Government [DCLG]. (2012). Investigation into Overheating in Homes: Literature review, (July). Retrieved from https://www.gov.uk/government/uploads/system/uploads/attachment_data/file/7 604/2185850.pdf

Her Majesties Government [HMG]. (2013). The Building Regulations, Conservation of fuel and power Approved Document Part L1A (2013 version), 48. Retrieved from UK Government planning 
portal: http://www.planningportal.gov.uk/uploads/br/BR_PDF_AD_L1A_2013. pdf

Kovats, S., Hajat, S. (2008) Heat stress and public health: A critical review. Annual Review of Public Health, 29 (9)19.15. http://doi.org/10.1146/annurev.publhealth.29.020907.090843

Larsen, T. S., \& Jensen, R. L. (2011). Comparison of measured and calculated values for the indoor environment in one of the first Danish Passive Houses, Aalborg University , Denmark, 14-16. Retrieved from http://www.ibpsa.org/proceedings/BS2011/P_1475.pdf

Maivel, M., Kurnitski J. \& Kalamees T. (2015). Field survey of overheating problems in Estonian apartment buildings. Architectural Science Review, 8628, 0-10. http://doi.org/10.1080/00038628.2014.970610

McLeod, R. S., Hopfe, C. J., \& Kwan, A. (2013). An investigation into future performance and overheating risks in Passivhaus dwellings. Building and Environment, 70, 189-209. http://doi.org/10.1016/j.buildenv.2013.08.024

Morgan, C., Foster, J., Sharpe, T., \& Poston, A. (2015). Overheating in Scotland: Lessons From 26 Monitored Low Energy Homes. CISBAT 2015 International Conference "Future Buildings and Districts - Sustainability from Nano to Urban Scale”. 167-172. Retrieved from http://radar.gsa.ac.uk/3719/

National House Building Council [NHBC]. (2012). Overheating in new homes: A review of the evidence. Retrieved from NHBC Foundation: http://www.nhbcfoundation.org/Publications/Research-Review/Overheating-innew-homes-NF46

National House Building Council [NHBC]. (2015). Homes through the decades. Retrieved from NHBC Foundation: http://www.nhbc.co.uk/NewsandComment/Documents/filedownloa d,59849,en.pdf

Nicol, J. F., \& Humphreys, M. a. (2002). Adaptive thermal comfort and sustainable thermal standards for buildings. Energy and Buildings, 34(6), 563-572. http://doi.org/10.1016/S0378-7788(02)00006-3

Office of the Deputy Prime Minister [ODPM]. (2004). Housing Health and Safety Rating System. Retrieved from UK

Government: https://www.gov.uk/government/uploads/system/uploads/attachme nt_data/file/15810/142631.pdf 
Ruud S, Lundin L. (2004) Bostadhus utan traditionellt uppvarmningssytem- resultat fran tva ars matningar. SP Report 2004:31. SP Technical Research Institute of Sweden. (Original in Swedish)

Parliament of the United Kingdom [UK]. (2006a) Stern Review on The Economics of Climate Change. 2006. Retrieved from: http://webarchive.nationalarchives.gov.uk/+/http:/www.hmtreasury.gov.uk/sternreview_index.htm

Parliament of the United Kingdom [UK]. (2006b) Pre-Budget Report; Investing in Britain's potential: Building our long-term future. Retrieved from: http://webarchive.nationalarchives.gov.uk/20071204131415/http://www.h m-treasury.gov.uk/media/2/2/pbr06_chapter7.pdf

Parliament of the United Kingdom [UK]. (2008) Climate Change Act 2008. Retrieved from UK Government: http://www.legislation.gov.uk/ukpga/2008/27/contents

Passive House Institute (http://www.passiv.de/en/index.php)

Peacock, a. D., Jenkins, D. P., \& Kane, D. (2010). Investigating the potential of overheating in UK dwellings as a consequence of extant climate change. Energy Policy, 38(7), 3277-3288. http://doi.org/10.1016/j.enpol.2010.01.021

Scottish Parliament. (2009). Climate Change (Scotland) Act 2009, 2009(asp 12), 68. Retrieved from: http://www.scotland.gov.uk/Topics/Environment/climatechange/scotlandsaction/climatechangeact

Scottish Government. (2015). Scottish Building Regulations: Technical handbook, Domestic. Retrieved from Scottish Government: http://www.gov.scot/Resource/0047/00478112.pdf

Stevenson, F., \& Leaman, A. (2010). Evaluating housing performance in relation to human behaviour: new challenges. Building Research \& Information, 38(5), 437-441. http://doi.org/10.1080/09613218.2010.497282

Taylor, J., Davies, M., Mavrogianni, a., Chalabi, Z., Biddulph, P., Oikonomou, E., ... Jones, B. (2014). The relative importance of input weather data for indoor overheating risk assessment in dwellings. Building and Environment, 76, 81-91. http://doi.org/10.1016/j.buildenv.2014.03.010

Zero Carbon Hub [ZCH]. (2014). Closing the Gap Between Performance, (July). Retrieved from: 
http://www.zerocarbonhub.org/sites/default/files/resources/reports/Closing_the_ Gap_Bewteen_Design_and_As-Built_Performance_Interim_Report.pdf

Zero Carbon Hub [ZCH]. (2015a). Overheating in Homes - The Big Picture. Retrieved from: http://www.zerocarbonhub.org/sites/default/files/resources/reports/ZCHOverheatingInHomes-TheBigPicture-01.1.pdf

Zero Carbon Hub [ZCH]. (2015b). Defining overheating - Evidence Review. Retrieved from:

http://doi.org/http://www.zerocarbonhub.org/sites/default/files/resources/reports/ ZCH-OverheatingEvidenceReview-Definitions.pdf

Zero Carbon Hub [ZCH]. (2015c) Assessing Overheating Risk - Evidence Review.

Retrieved

from: http://www.zerocarbonhub.org/sites/default/files/resources/reports/ZCHOverheatingEvidenceReview-Methodologies.pdf 